\title{
U-SHAPED MICROSTRIP PATCH ANTENNA FOR COMMUNICATION
}

\author{
Ms. P. D. Swami \\ Department of Digital Communication \\ M.B.E.S. COE, Ambajogai, Maharashtra, India.
}

\begin{abstract}
One of the emerging technology in wireless communication system in these days can be said as the Ultra Wideband (UWB) antennas which are giving a wide range of spectrum against the other radio communication systems. Many researches have been attracted towards this modern recipe to serve continuously crunching electronic devices providing as prominent bandwidth. The proposed system design implemented $U$-shaped slot on radiating monopole antennas. The proposed antenna design consist of uses a microstrip fed which utilizes alongside ground plane. Microstrip patch line having impedance of $50 \Omega$ is fed into the antenna. Proposed system can be realized by using the frequency ranges of 3 to $10.6 \mathrm{GHz}$ having band notching range in between $5.1 \mathrm{GHz}$ to $5.8 \mathrm{GHz}$ accordingly. The simulation studies are taken for the consideration and testing of antenna performance by maintaining the other required parameters as that of the free space environment without disturbance.
\end{abstract}

Keywords-U-shaped, VSWR, patch antenna, microstrip

\section{INTRODUCTION}

Antennas play a very important role in the field of wireless technologies by serving an uninterrupted service to the users. As in general most of our daily communication takes place over a wireless media so it's worth to say that it's an essential thing to take consideration of antenna for a telecommunications with its worthy features against wired one. Usually these antennas are come in many shapes according to its applications in real time and state of transmission of data. And each type of antenna have their own state of properties and advantages for their use as compared to others. The shapes can be mostly seen by molding them in parabolic shape, creating patches, slots, and by folding them. These can be said as the backbone and the driving force behind the recent advances in wireless communication technology. In recent decades only the increasing demand of wireless communication technologist are getting interest in its development using a microstrip and array elements.

Studies are also carried out with printed antennas by considering its extra beneficial properties like its small size, lightweight, minimum cost, ease of handle and care, easy to install and flexible design patterns and many more. As we have focused our study on microstrip patch antennas with it's
Prof. V. V. Yerigeri, Prof. S. M. Patil

Department of Post Graduation

M.B.E.S. COE, Ambajogai, Maharashtra, India. patch radiation components along with its ground plane at other side of dielectric substrate. Obviously the patch component is made up of radiating metal compound. Usually both the patch component with feed lines were photo etched upon the dielectric substrate. Microstrip patch antennas radiate primarily because of fringing fields between patch edge and ground plane.

The rest of paper work is disciplined as below. Related work up to date with its observation and analysis is given in section II. System design and modelling is described in section III. Section IV describes the simulation part and the result and analysis accordingly. Conclusions are given in section $\mathrm{V}$.

\section{RELATED WORK}

As we have discussed $\mathrm{n}$ introduction the microstrip patch antennas (MPAs) are becoming most popular design for the antenna developers for its features of small outline and easy to manufacture and use, well-matching for both planar and nonplanar surfaces, allow multi frequency operation to be achieved. The antenna has two fold making the structure Lshaped along the ground plane. Due to wave excitation transmission generates circular polarization. This excitation also harvests currents with alterations in quadrature phase upon the L-shaped segments. A ground plane is placed at a quarter-wavelength away from the L-shaped radiator. In the intervening time, the ground plane, generates a guided radiation pattern. Proposed system is made up of $2 \times 2$ elements aligned in a line manufactured using two layers of printed circuit board [2]. A vertical monopole antenna having a directional radiation pattern proposed in this paper and discussed in further below. Designed antenna with monopole is positioned straight up on the half-and-half finite ground plane of perfect magnetic conductor (PMC) and perfect electric conductor (PEC). Dimension of the ground is kept at $1 \lambda 0$ which helps us to take a required measurements and install set up. As of the general design of monopole antenna, the surface currents on a ground plane are cancelled. This happens due to the symmetrical ground regarding the monopole concept [3]. This paper presents a miniaturized directional antenna design for ultra-wideband (UWB) applications. The design is based on a monopole-like slot structure printed on an FR4 printed circuit board (PCB) 
backed by a cavity in order to achieve directionality [6]. A novel wideband unidirectional planar monopole antenna is presented in this communication. Unidirectional radiation is achieved by simply connecting the ground plane to the monopole using a shorting side-stub. By doing so, one edge of the radiator is shorted to the ground plane which results in non-radiation of the out-of-phase electric currents at that shorted end. Since only one side mainly radiates, hereby term this as - a quasi-radiator.

\section{A. Microstrip Antennas}

Conventional antennas and microstrip antennas are crucial for application in modern communication and navigation systems. Unlike conventional microwave antennas, microstrip antennas can conform to both planar and non-planar surfaces. Military or civilian applications such as space and weight restricted aerospace vehicle structure microstrip antennas are better suited in comparison to conventional antennas.[7-10]

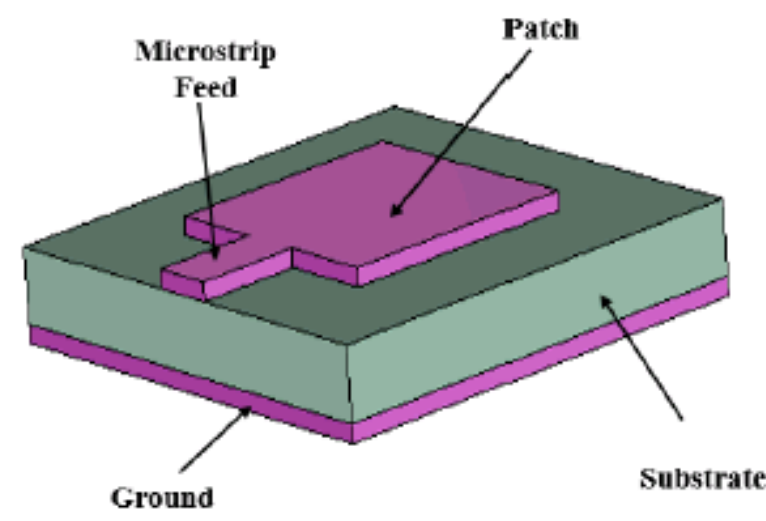

Fig. 1: Microstrip Patch Antenna

Microstrip patch antennas can be classified based on their physical parameters. Different types of patches have different purposes. There are square, rectangular, circular, dipole, printed and elliptical configurations. There are different slots in patch antenna configuration such as A-slot, U-slot, H-slot, E-slot patch antennas. They are used for different frequency bands.[11-14]

\section{SYSTEM MODEL}

- This project proposes an Ultra-wide band (UWB) antenna with band notched characteristics with the help of Ushaped slots on radiating patch and ground.

- The size of each and every parameter used for designing and optimizing the antenna was used for better return loss curve, ultra-wide band operations.

- U shaped slotted monopole antenna make well suited for UWB applications (5.1 to $5.8 \mathrm{GHz}$ ).
- The antenna may be used for applications in satellite communication band, $\mathrm{X}$ band for satellite.

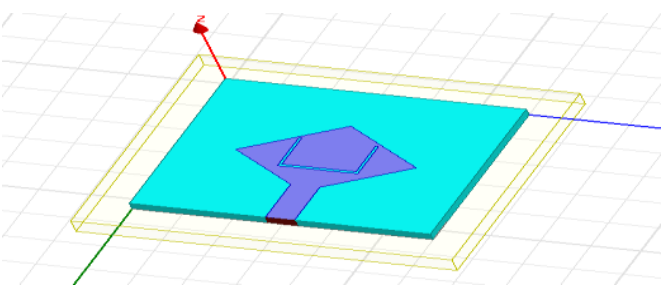

Fig. 2: Antenna design of proposed system

The UWB of this antenna is mainly implemented by the U-shaped slot. The U-shaped slot can provide with superimposed perturbation orthogonal current distributions on the outer contour surface at lower frequency. [15-17]

\section{Result ANALysis AND Simulations}

Based on the results from the simulations and measurements, it is clear that the single layer microstrip antenna has a very narrow bandwidth. There is a requirement to use a bandwidth enhancement technique in this microstrip antenna and the slot loaded technique is deployed. The proposed antenna and simulations are shown in the fig. 3-7. The boundary assignment to manufacture is given in the fig. 3 to cut the antenna accordingly. Fig. 4 shows the patch to be created in the antenna. The ground plane in fig. 5 should be extended so that it must be greater than the edge of patch by at least more than 2 times the board thickness for proper working.

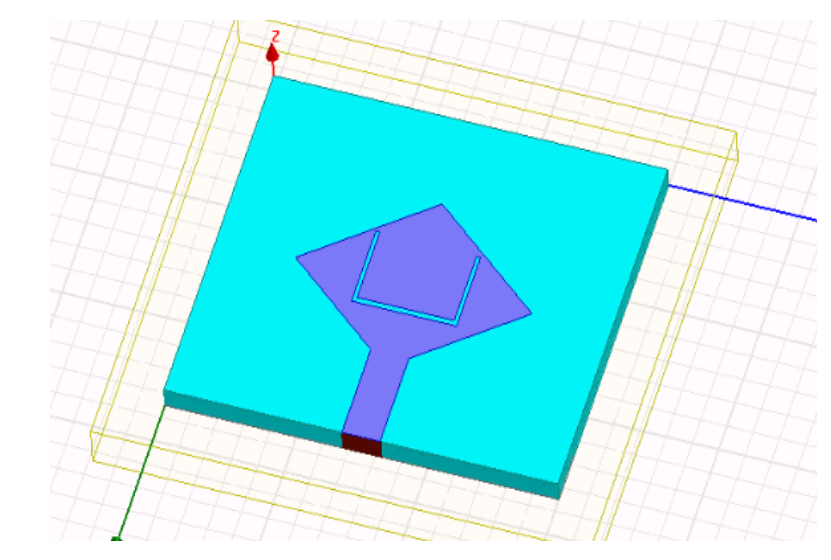

Fig. 3: Boundary Assignment

The radiation box (fig. 6) should be defined into the system so that the radiation pattern can be observed by absorbing radiation. 


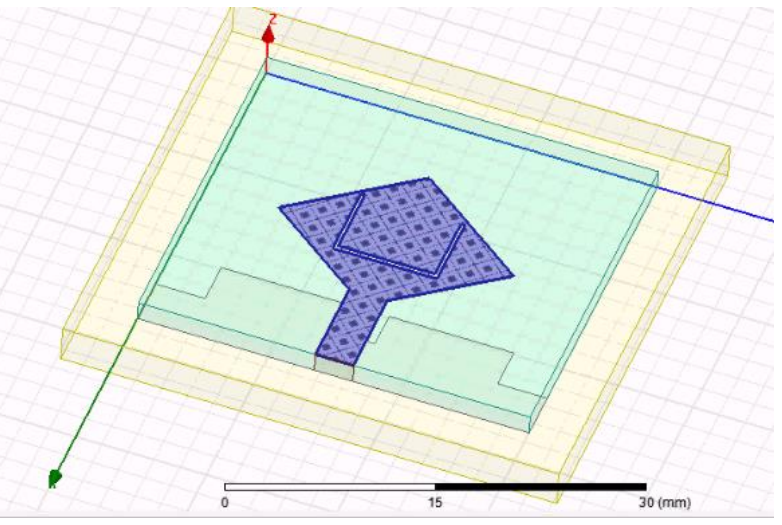

Fig. 4: Patch

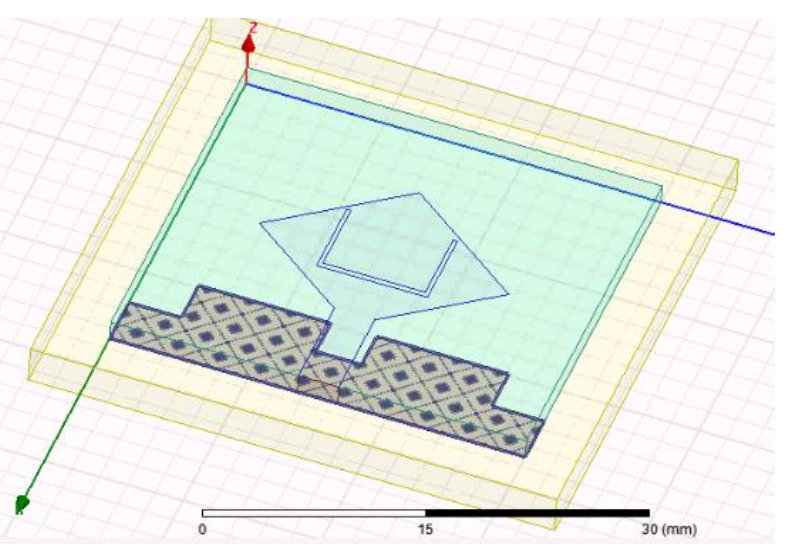

Fig. 5: Ground

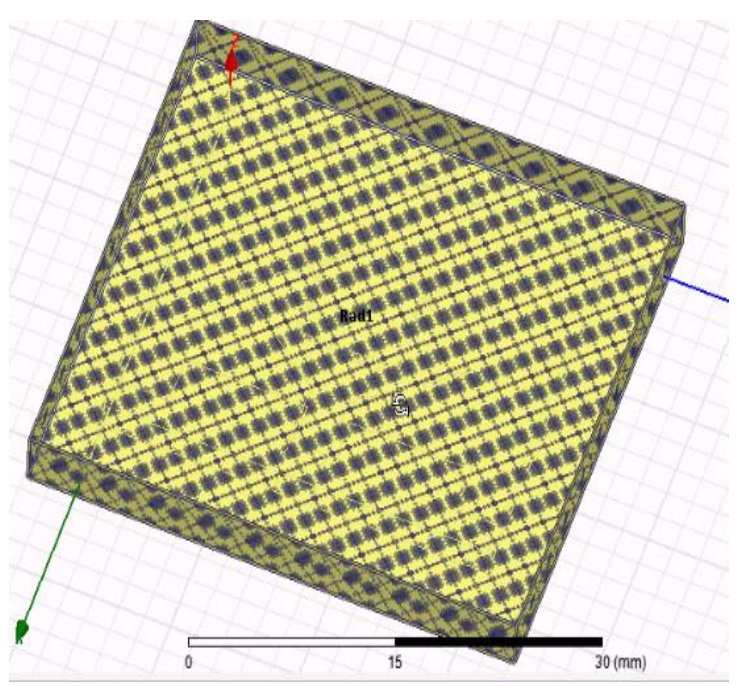

Fig. 6: Radiation Box

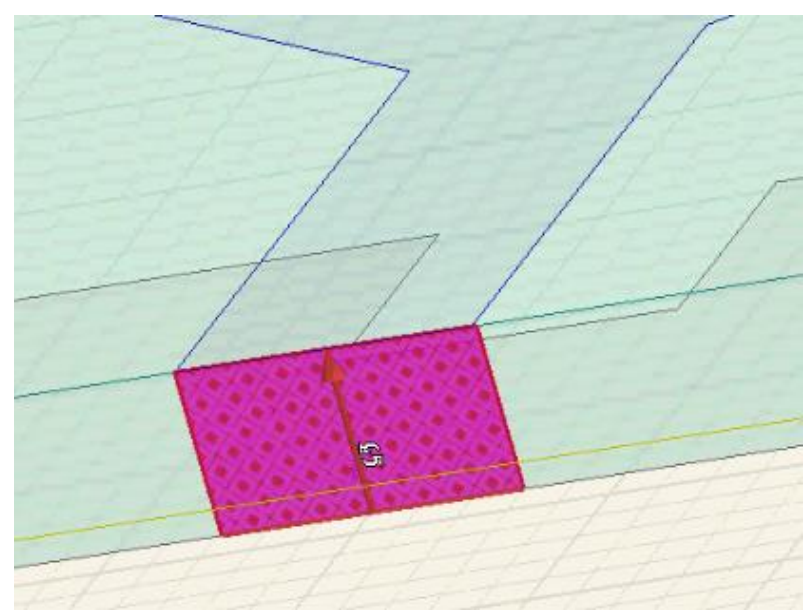

Fig. 7: Excitation

A. Volatage Standing Wave Ratio (VSWR):

Voltage Standing Wave Ratio (VSWR) is an indication of the quality of the impedance match. VSWR is often abbreviated as SWR. A high VSWR is an indication the signal is reflected prior to being radiated by the antenna. VSWR and reflected power are different ways of measuring and expressing the same thing. When the condition of matching is not satisfied, that means, $\mathrm{ZL}=\mathrm{Z}$, then the power may be reflected back which leads to the creation of standing waves. The standing waves can be characterized by a parameter called Voltage Standing Wave Ratio (VSWR). The VSWR expresses the degree of match between the transmission line and the antenna. (fig. 8)

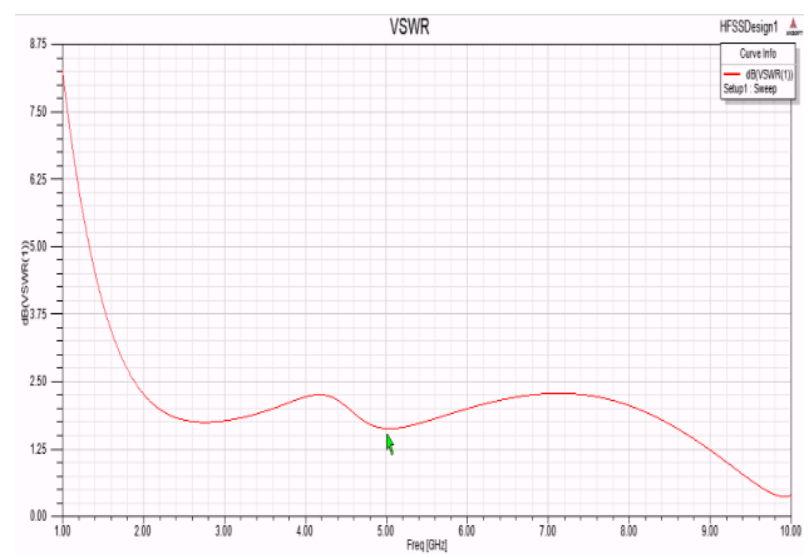

Fig. 8: Voltage Standing Wave Ratio

\section{B. Gain:}

Gain is an antenna property dealing with an antenna's ability to direct its radiated power in a desired direction, or synonymously, to receive energy preferentially from a desired direction. The gain of the proposed antenna is $\mathrm{dB}$. (fig. 9) 
International Journal of Engineering Applied Sciences and Technology, 2020

Vol. 5, Issue 3, ISSN No. 2455-2143, Pages 643-647

Published Online July 2020 in IJEAST (http://www.ijeast.com)
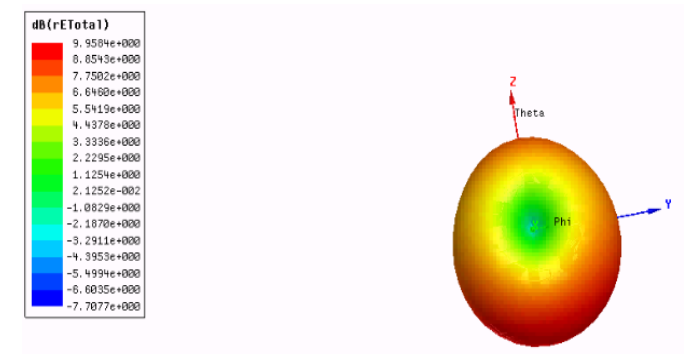

Fig. 9: Gain

\section{Radiation Pattern:}

For a linearly polarized antenna, performance is often described in terms of its Principal E- and H-plane patterns. The E-plane is defined as "the plane containing the electricfield vector and the direction of the maximum radiation." The radiation pattern of an antenna is a plot of the far-field radiation properties of an antenna as a function of the spatial co-ordinates which are specified by the elevation angle $(\theta)$ and the azimuth angle $(\varphi)$. Because this parameter was so important to our software simulations we needed to understand it completely. More specifically it is a plot of the power radiated from an antenna per unit solid angle which is nothing but the radiation intensity. It is an extremely parameter as it shows the antenna's directivity as well as gain at various points in space. It serves as the signature of an antenna and one look at it is often enough to realize the antenna that produced it. Radiation or antenna pattern describes the relative strength of the radiated field in various directions from the antenna at a constant distance. The radiation pattern is a "reception pattern" as well, since it also describes the receiving properties of the antenna. The radiation pattern is three-dimensional, but it is difficult to display the three-dimensional radiation pattern in a meaningful manner. (fig.10)
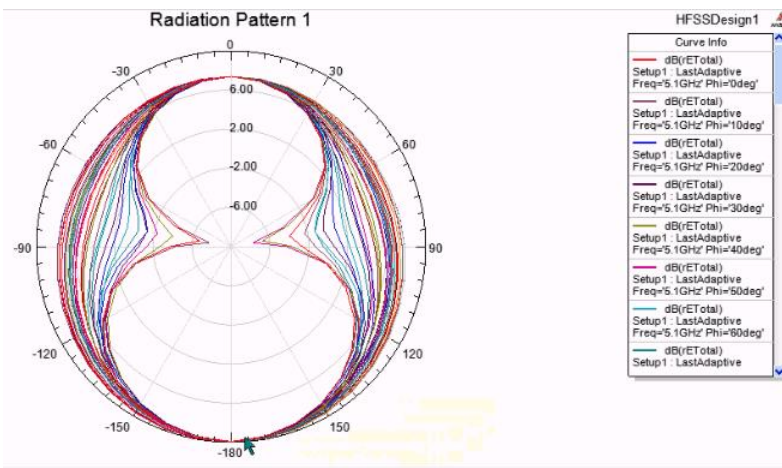

Fig. 10: Radiation Pattern

\section{Return Loss:}

It is a parameter which indicates the amount of power that is "lost" to the load and does not return as a reflection. Hence a parameter to indicate how well the matching between the transmitter and antenna has taken place. The bandwidth can be calculated from the return loss (RL) plot. (fig. 11)

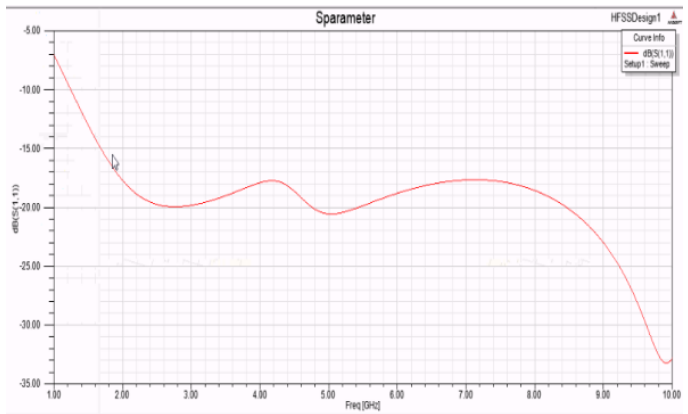

Fig.11: S Parameter

\section{CONCLUSION}

The technique for enhancing bandwidth of the Microstrip antenna has been shown and it can be used for various wireless applications. As mentioned, this technique has its advantages such as it does not increase the lateral size of the microstrip antenna. Therefore, trade-of issues need to be considered in this design. Simulations and measurements on the new proposed antenna configuration have provided a useful design for a wide bandwidth.

\section{REFERENCE}

[1] P. Gundeti, T. K. George, "Performance analysis of a compact directional monopole antenna", IEEE Applied Electromagnetic Conf. pp. 1-4, 2011

[2] D. J. Bisharat, S. Liao, Q. Xue, "Wideband unidirectional circularly polarized antenna with L-shaped radiator structure", IEEE Antennas and Wireless Propag. Lett., vol. 16, pp. 12-15, 2017.

[3] J.-G. Lee, J.-H. Lee, "Directional monopole antenna using half PMC and PEC ground plane", Microw. Opt. Technol. Lett., vol. 60, pp. 979-983, 2018.

[4] Kildal, P.-S, "Definition of artificially soft and hard surfaces for electromagnetic", IEEE Trans. Antennas Propag., vol. 38, no. 10, pp. 1537-1544, 1990.

[5] M. Klemm, I.Z. Kovacs, G.F. Pendersen, G. Troster, "Novel small size directional antenna for UWB WBAN/WPAN applications," IEEE Trans. Antennas Propag., vol. 53, pp. 3884-3896, 2005

[6] X. Qing, Z. N. Cheng "A miniaturized directional UWB antenna", Proc. IEEE Antennas and Propag Society, Int. Symp., pp. 1470-1473, 2011. 
[7] S. Xiang, Y. Wu, M. Zhu, "Design of wide band high gain unidirectional antenna with low profile", IEEE Antennas and Propag Society, Int. Symp., pp. 583-584, 2017.

[8] L. Ge, K. M. Luk, "Band-Reconfigurable unidirectional antenna:A simple efficient magneto-electric antenna for cognitive radio applications", IEEE Trans. Antennas Propag. Mag., vol. 58, no. 2, pp. 18-27. 2016.

[9] A. Locatelli, D. Modotto, F. M. Pigozzo, S. Boscolo, E. Autizi, C DeAngelis, A.-D. Capobianco, M. Midrio, "Increasing directionality of planar ultra-wideband antennas", Microw. Opt. Technol. Lett., vol. 52, pp. 78-82, 2010.

[10] A. Locatelli, D. Modotto, F. M. Pigozzo, S. Boscolo, E. Autizi, C DeAngelis, A.-D. Capobianco, M. Midrio, "A planar, differential, and directive ultrawideband antenna", IEEE Trans. Antennas Propag., vol. 58, no. 7, pp. 78-82, 2010

[11] G.-M. Zhang, J.-S. Hong, B.-Z Wang, G. Song, P. Zhang, "Compact wideband unidirectional antenna with a reflector connected to the ground using a stub", IEEE Antennas Wireless Propag.Lett., vol. 10, pp. 1186-1189, 2011.

[12] J. J. Golezani, M. Abbak, I. Akduman, "Modified directional wide band printed monopole antenna for use in radar and microwave imaging applications", Progress in Electromag. Research Lett., vol. 33, pp. 119-129, 2012.

[13] M. S. Ellis, Z. Zhao, J. Wu, Z. Nie, Q.-H. Liu, "Unidirectional planar monopole ultrawideband antenna using wrench-shaped feeding structure", Electron. Lett., vol. 50, no. 9, pp. 654-655, April. 2014

[14] M. Cabedo-Fabres, E. Antonia-Daviu, A. ValeroNogueira, M. Ferrando-Battaler, "Analysis of wide band planar monopole antennas using characteristic modes", Proc. IEEE APS Int. Symp. Dig., vol. 3, pp. 733-736, 2003.

[15] J. Liang, C. C. Chiau, X. Chen, C. G. Parini, "Study of a printed circular disc monopole antenna for UWB systems", IEEE Trans. Antennas Propag., vol. 53, no. 11, pp. 35003504, 2005

[16] G. Kumar and K. P. Ray, Broadband Microstrip Antennas, Boston, M.A: Artech House, 2003.

[17] S. Nikolaou, G. E. Ponchak, "Compact Cactus-Shaped Ultra Wide-Band Monopole on Organic Substrate" IEEE Ant. Prop. Society Int. Symp, AP-S. IEEE, pp. 4637-4640, 2007. 